Cite this: Phys. Chem. Chem. Phys., 2013, 15, 11386

Received 25th February 2013, Accepted 9th May 2013

DOI: $10.1039 / c 3$ cp50841b

www.rsc.org/pccp

\section{Luminescence spectroscopy of singlet oxygen enables monitoring of oxygen consumption in biological systems consisting of fatty acids}

\author{
Anita Gollmer, ${ }^{*}$ Johannes Regensburger, Tim Maisch and Wolfgang Bäumler
}

\begin{abstract}
The interaction of singlet oxygen $\left({ }^{1} \mathrm{O}_{2}\right)$ generated in a photosensitized process with well-known reference photosensitizers Perinaphthenone (PN) and TMPyP is investigated in a model system consisting of fatty acids and the respective exogenous photosensitizer (PS) in solution by direct detection of the luminescence photons of ${ }^{1} \mathrm{O}_{2}$ at $1270 \mathrm{~nm}$. Such a model system is a first approach to mimic the complex environment of ${ }^{1} \mathrm{O}_{2}$ in a biological cell which consists mainly of water, proteins, sugars and lipids. Firstly, the important issue of oxygen consumption is evaluated which has to be considered during luminescence detection of ${ }^{1} \mathrm{O}_{2}$. It is known that the luminescence signal of ${ }^{1} \mathrm{O}_{2}$ is dependent on the oxygen concentration of the environment. Cellular components such as lipids represent oxygen consumers due to peroxidation of their unsaturated double bonds. Secondly, the experimental conditions for this model system regarding oxygen consumption are optimized to estimate the rates and rate constants of the coupled system. Thirdly, the triplet decay of the PS can provide more precise information about the actual oxygen concentration close to the PS and can be used, therefore, as a more precise method to determine the oxygen concentration in more complex systems such as a biological cell. The aim is to get a better understanding of photosensitized reactions of ${ }^{1} \mathrm{O}_{2}$ with cellular components to further improve methodologies, in particular at a cellular level using luminescence spectroscopy. In conclusion, luminescence detection might be a helpful tool to monitor precisely and promptly changes in oxygen concentration in a complex environment.
\end{abstract}

\section{Introduction}

Molecular oxygen is, without doubt, a very essential molecule on earth. ${ }^{1}$ Singlet oxygen $\left({ }^{1} \mathrm{O}_{2}\right)$, the lowest excited electronic state of ground state oxygen $\left({ }^{3} \mathrm{O}_{2}\right)$, can be generated in a photosensitized process by various light absorbing molecules, so-called photosensitizers (PS). ${ }^{2}$ The photo-activated sensitizer transfers energy from its triplet state $\left(\mathrm{T}_{1}\right)$ to ${ }^{3} \mathrm{O}_{2}$. Furthermore, ${ }^{1} \mathrm{O}_{2}$ is one of the most active intermediates involved in oxygenation reactions in chemical and biological systems. ${ }^{2-5}{ }^{1} \mathrm{O}_{2}$ has a unique and rich chemistry that is substantially different from that of ${ }^{3} \mathrm{O}_{2}$ and other reactive oxygen species (ROS). ${ }^{4}$ In photodynamic therapy (PDT) biological tissue that is undesired, such as tumor or bacterial infected tissue, is destroyed with high specificity. ${ }^{6,7}{ }^{1} \mathrm{O}_{2}$ is known to play the major role in PDT. ${ }^{8}$ The cellular processes that involve ${ }^{1} \mathrm{O}_{2}$ have not yet been fully understood, in particular in

Department of Dermatology, University Hospital Regensburg, 93042 Regensburg, Germany. E-mail: anita.gollmer@klinik.uni-regensburg.de; Fax: +49-941-944-8943; Tel: +49-941-944-8945 photo-induced cell death, e.g. the oxidation of certain proteins and fatty acids. ${ }^{2,3,6,9}$ However, generation of ${ }^{1} \mathrm{O}_{2}$ can immediately change its environment, in particular in biological cells that consist of proteins and lipids which can chemically react with ${ }^{1} \mathrm{O}_{2} \cdot{ }^{10,11}$

A direct and precise method to detect ${ }^{1} \mathrm{O}_{2}$ is the measurement of its luminescence at about $1270 \mathrm{~nm}$, which has been frequently applied..$^{10-19}$ In order to gain a detailed insight into the interaction of a photo-activated PS with molecular oxygen, the measurement of the complete time dependence of ${ }^{1} \mathrm{O}_{2}$ luminescence is a powerful tool. ${ }^{20}$ To evaluate the luminescence signals, the well-known theoretical model reported by Parker et al. is used, ${ }^{21,22}$ which describes the time-dependent population of the triplet $\mathrm{T}_{1}$ state of a PS and the subsequent generation of ${ }^{1} \mathrm{O}_{2}$ by energy transfer.

In the past years, the technology and therefore the sensitivity of optical detectors have substantially improved. Despite the very low quantum efficiency of radiative transition from ${ }^{1} \mathrm{O}_{2}$ to ${ }^{3} \mathrm{O}_{2},{ }^{1} \mathrm{O}_{2}$ can be detected directly by its luminescence in the near infrared, in pure solutions, in fatty acids and lipids, 
and even in living cells or bacteria. ${ }^{12-14,17,23}$ At a single cell level, Kuimova et al. showed a dramatic increase in intracellular viscosity upon generation of ${ }^{1} \mathrm{O}_{2}$ using the direct luminescence detection. $^{10}$

Nevertheless, the interpretation of the luminescence signals and the respective conclusions remain challenging and sometimes puzzling, because many parameters influence the course and the meaning of such luminescence signals at the same time. Physical and chemical quenching of ${ }^{1} \mathrm{O}_{2}$ by cellular molecules can change the luminescence signal. In particular chemical reaction of ${ }^{1} \mathrm{O}_{2}$ with cellular biomolecules changes the luminescence signal twofold - by shortening the lifetime of the ${ }^{1} \mathrm{O}_{2}$ state and by oxygen consumption via peroxidation of lipids or proteins, ${ }^{24,25}$ which affects the quenching of the photosensitizer triplet $\mathrm{T}_{1}$-state by oxygen while photosensitized generation of ${ }^{1} \mathrm{O}_{2}$ is continued. ${ }^{21,26}$

This correlation between ${ }^{1} \mathrm{O}_{2}$ luminescence and oxygen consumption results in two important issues, ${ }^{27}$ which were studied in the present work using a simplified model of fatty acids and photosensitizers. Firstly, there is an urgent need to consider oxygen consumption when detecting ${ }^{1} \mathrm{O}_{2}$ luminescence in an environment that contains oxygen consumers like lipids or proteins. Secondly, the change in rates of the ${ }^{1} \mathrm{O}_{2}$ luminescence signal might enable monitoring of oxygen concentration during irradiation.

The experiments were performed with the well-known Perinaphthenone (PN) which is a lipophilic photosensitizer, and TMPyP, a hydrophilic photosensitizer, in ethanol solution. $\mathrm{PN}$ and TMPyP show a high quantum yield of ${ }^{1} \mathrm{O}_{2}$ generation. ${ }^{15,28}$ Both PN and TMPyP are therefore frequently used as reference PS in solution experiments and in particular TMPyP for cell suspension experiments and even at a single cell level. ${ }^{29,30}$ Oxygen consumption caused by adding different fatty acids to the PS solution was monitored using a needle sensor as well as by luminescence spectroscopy.

\section{Materials and methods}

\section{Preparation of solutions}

5,10,15,20-Tetrakis( $N$-methyl-4-pyridyl)-21 $H, 23 H$-porphine (TMPyP) (Sigma-Aldrich, Steinheim, Germany) or Perinaphthenone (PN) (Acros Organics, Belgium, purity 97\%) were dissolved in ethanol. Stearic acid, oleic acid, linoleic acid, and linolenic acid (all purity $\sim 99 \%$ ) were dissolved in ethanol to yield a final concentration of $50 \mathrm{mmol} \mathrm{L}{ }^{-1}$. All fatty acids were purchased from Sigma-Aldrich (Steinheim, Germany).

\section{Absorption spectra}

The absorption cross-section of the photosensitizers was measured at room temperature with a Beckman DU640 spectrophotometer (Beckman Instruments $\mathrm{GmbH}$, Munich, Germany) using a quartz cuvette (QS-101, Hellma Optik, Jena, Germany).

\section{Oxygen concentration in solution}

The oxygen concentration in solution was measured in the cuvette using a needle sensor (MICROX TX3, PreSens GmbH,
Regensburg, Germany). Data sampling was accomplished at $1 \mathrm{~Hz}$, and the shown curves were smoothened using a bi-square routine.

\section{Luminescence experiments}

All solutions were transferred into a cuvette (QS-101, Hellma Optik, Jena, Germany). The sensitizers were excited using either a frequency-doubled or tripled Nd:YAG laser (PhotonEnergy, Ottensoos, Germany) with a repetition rate of $2.0 \mathrm{kHz}$ (wavelength $532 \mathrm{~nm}$ (TMPyP) or $355 \mathrm{~nm}(\mathrm{PN})$, pulse duration $70 \mathrm{~ns}$ ). The ${ }^{1} \mathrm{O}_{2}$ luminescence at $1270 \mathrm{~nm}$ was detected in the nearbackward direction with respect to the excitation beam using an infrared sensitive photomultiplier (R5509-42, Hamamatsu Photonics Deutschland GmbH, Herrsching, Germany) with a rise time of about 3 ns. The details of the setup are described elsewhere. ${ }^{31}$ The luminescence signal was detected at $1270 \mathrm{~nm}$ using an appropriate interference filter (FWHM $10 \mathrm{~nm}$ ) in front of the photomultiplier.

\section{Determination of singlet oxygen luminescence decay and rise time}

The luminescence intensity of ${ }^{1} \mathrm{O}_{2}$ is given by ${ }^{21}$

$$
I(t)=\frac{C}{\beta_{1}-\beta_{2}}\left(\mathrm{e}^{-\beta_{2} t}-\mathrm{e}^{-\beta_{1} t}\right)
$$

The constant $C$ was used to fit the luminescence signal and is a product of the oxygen concentration $\left[\mathrm{O}_{2}\right]$, the rate constant for the deactivation of the triplet state of the PS by ${ }^{1} \mathrm{O}_{2}, k_{\mathrm{T}_{1} \Delta}$, and the concentration of the PS in the triplet state at time zero $\left[\mathrm{T}_{1}\right]_{0} . \beta_{2}$ and $\beta_{1}$ are the decay and rise rates, respectively. The detected signals were fitted with least square fit routines of Mathematica 5.2 (Wolfram Research, Berlin, Germany). The experimental error of the fit was estimated to be $15 \%$ of the values, which are determined by the fit. The integral of eqn (1) from $t=0 \rightarrow \infty$ yields the luminescence energy. For better comparison, the integral value was calculated per mole of the respective substance.

All rates and rate constants of the entire differential equation system are dependent on $\beta_{1}$ and $\beta_{2}$ (see eqn (2) and (3) below). To determine the rates and rate constants of the entire system (photosensitizer and oxygen molecule) three series of measurements have to be performed. Therefore, the time-resolved singlet oxygen luminescence is detected at different photosensitizer, oxygen or quencher concentrations and fitted to obtain $\beta_{2}$ and $\beta_{1}$ as described above. Firstly, the underlying differential equations are solved using different values for rates and rate constants to approximate the experimentally obtained rates $\beta_{1}$ and $\beta_{2}$ (solid lines in Fig. 4-6). Secondly, that fitting procedure yields the theoretical values of $K_{\mathrm{T}_{1}}$ and $K_{\Delta}$. In our study it is shown that the theoretical values deviate from the experimentally obtained data at high oxygen and high photosensitizer concentrations due to oxygen consumption and this allows monitoring of oxygen consumption. The evaluation of the data is described in detail by Baier et al. ${ }^{21}$ 


\section{Results and discussion}

When a photosensitizer generates ${ }^{1} \mathrm{O}_{2}$ inside a living cell, processes such as peroxidation of fatty acids lead to oxygen consumption to a still unknown extent. In addition, intact cells are a closed system that exhibit less oxygen concentration as compared to the aqueous environment outside the cell under in vitro or in vivo conditions. ${ }^{32}$

By comparing experimental and theoretical values, ${ }^{21}$ one can provide details of the dependence of the ${ }^{1} \mathrm{O}_{2}$ luminescence on the various experimental conditions, which helps to interpret the meaning and the reliability of such signals. This is of particular importance when the sub-cellular environment of ${ }^{1} \mathrm{O}_{2}$ is changed by ${ }^{1} \mathrm{O}_{2}$ itself during the time span that is necessary for its detection. As a first approach to this complex environment, we evaluated a basic model that contained the PS in solution, oxygen and fatty acids, whereas the latter played the role of oxygen consumers. Fatty acids such as oleic and linoleic acid are common constituents of many cellular membranes. ${ }^{33}$

As a first step, we quantified the extent of oxygen consumption. The PS was added to ethanol solutions that contained fatty acids with different number of double bonds but with the same chain length. The concentrations of stearic acid (18:0), oleic acid (18:1), linoleic acid (18:2), or linolenic acid $(18: 3)$ were $50 \mathrm{mmol} \mathrm{L}^{-1}$ each. The brackets show the ratio of the number of carbon atoms to the number of double bonds of the respective fatty acids. The respective solutions were filled in a cuvette $(3.3 \pm 0.1 \mathrm{ml})$ that was hermetically closed. A needle sensor continuously reported the overall oxygen concentration in the sealed cuvette during irradiation. To minimize oxygen diffusion effects, we thoroughly stirred the solutions during irradiation. All experiments were started with air-saturated solutions $\left(\left[\mathrm{O}_{2}\right]=1850 \mu \mathrm{mol} \mathrm{L}{ }^{-1}\right.$, ethanol $)$.

\section{Oxygen consumption in fatty acid solutions with the photosensitizer PN}

PN $\left(200 \mu \mathrm{mol} \mathrm{L}^{-1}\right)$ in ethanol solution was irradiated without and with the different fatty acids at $355 \mathrm{~nm}(100 \mathrm{~mW})$. During the time span of 10 min irradiation, the oxygen concentration decreased and the decrease was maximal for the fatty acid with three double bonds (linolenic acid) (Fig. 1a). The decrease of oxygen concentration in the suspension could be fitted with the zero-order equation for photochemical reactions within the first $4 \mathrm{~min}$. The fits yielded the respective consumption of oxygen per second, which are listed in Table 1. After that time, the fit clearly deviates from the data points, whereas the complete time span could not be fitted by any other order of reactions. Obviously, other processes occur in solution during the long-lasting irradiation.

Without fatty acids, irradiation of PN in ethanol showed oxygen consumption (Fig. 1a) yielding a rate constant of $0.6 \mu \mathrm{mol} \mathrm{L}^{-1} \mathrm{~s}^{-1}$ (Table 1). Kuznetsova et al. have already shown chemical alteration of PN in ethanol, whereas PN is reduced to a ketyl radical which can interact with oxygen and alcoholic radicals leading to oxygen consumption in the system only by the ketyl radical (compound 1a in Fig. 2) ${ }^{34}$ The reaction products are hydroxyphenalenone and $\alpha$-hydroxyethylphenalenone
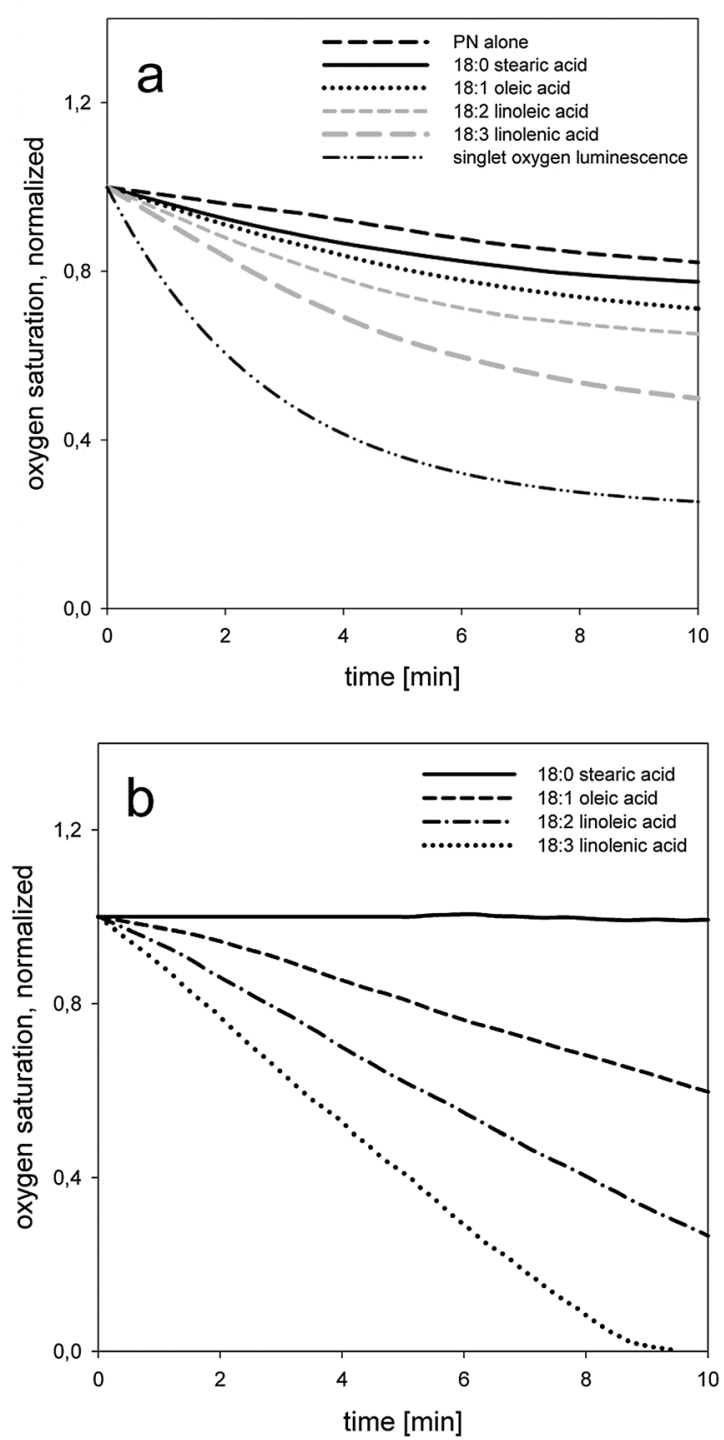

Fig. 1 The oxygen concentration measured in the sealed cuvette that contained different fatty acids at $50 \mathrm{mmol} \mathrm{L}^{-1}$ together with the photosensitizer PN at $200 \mu \mathrm{mol} \mathrm{L}{ }^{-1}$ (a) or together with TMPyP at $25 \mu \mathrm{mol} \mathrm{L}^{-1}$ (b). Both photosensitizers produced ${ }^{1} \mathrm{O}_{2}$ molecules at a rate of about $10^{17} \mathrm{~s}^{-1}$. For comparison, the fit of the integrated luminescence signal of ${ }^{1} \mathrm{O}_{2}$ (see Fig. 3) is added to (a).

Table 1 Oxygen consumption by fatty acids

\begin{tabular}{llll}
\hline Fatty acid & $\begin{array}{l}\text { Length: } \\
\text { double bonds }\end{array}$ & $\begin{array}{l}\text { Rate constant } \\
\left(\mu \mathrm{mol} \mathrm{L} \mathrm{s}^{-1}\right) \\
(\text { with TMPyP) }\end{array}$ & $\begin{array}{l}\text { Rate constant } \\
\left(\mu \mathrm{mol} \mathrm{L} \mathrm{s}^{-1}\right) \\
(\text { with PN) }\end{array}$ \\
\hline None & 0 & 0.6 \\
Stearic acid & $18: 0$ & 0 & 0.9 \\
Oleic acid & $18: 1$ & 1.2 & 1.2 \\
Linoleic acid & $18: 2$ & 2.3 & 1.6 \\
Linolenic acid & $18: 3$ & 3.6 & 2.3 \\
Generation of ${ }^{1} \mathrm{O}_{2}$ molecules & $0.9 \times 10^{17} \mathrm{~s}^{-1}$ & $1.0 \times 10^{17} \mathrm{~s}^{-1}$
\end{tabular}

(compound 8 and compound 2 in Fig. 2, respectively). It was likewise assumed that PN abstracted hydrogen from the solvent by its excited triplet $\mathrm{T}_{1}$ state leading to hydroxyethyl radicals (Fig. 2). ${ }^{35}$ 


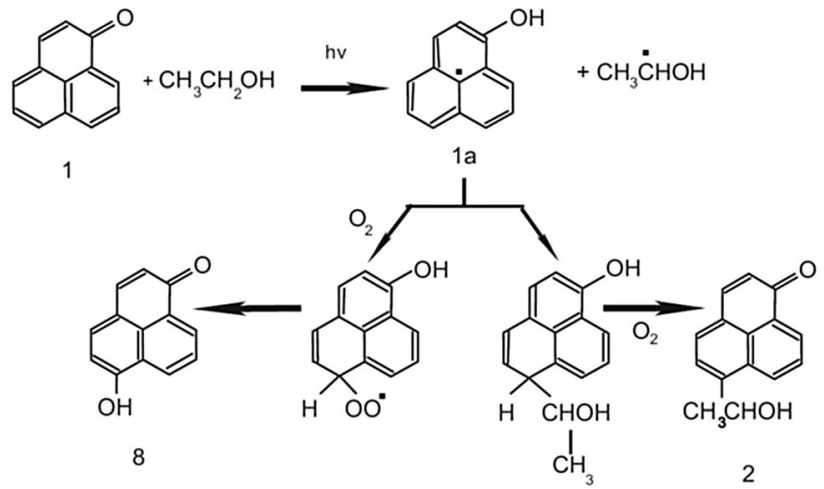

Fig. 2 Radical formation of PN in EtOH. ${ }^{34}$ Molecule (1) represents PN, (1a) the ketyl radical, (8) hydroxyphenalenone and (2) $\alpha$-hydroxyethylphenalenone.

When adding stearic acid as a fatty acid without any double bonds to PN solution, the rate of oxygen consumption increased to $0.9 \mu \mathrm{mol} \mathrm{L}{ }^{-1} \mathrm{~s}^{-1}$ (Fig. 1a). After light absorption by PN, the energy is rapidly transferred to its triplet state yielding two major options: either energy is transferred to generate ${ }^{1} \mathrm{O}_{2}$ or hydrogen is abstracted from the solvent ethanol to generate ketyl radicals that interact with oxygen and cause oxygen consumption (Fig. 2). Regarding the subsequent process of oxygen consumption, stearic acid with no double bonds cannot chemically quench oxygen resulting in oxygen consumption in the solution. However, the stearic acid offers a substantial amount of hydrogen atoms, which additionally can be abstracted by the PN triplet $\mathrm{T}_{1}$ state. As a consequence, this could enhance the generation of ketyl radicals that additionally can trap oxygen leading to oxygen consumption (Fig. 2).

When adding fatty acids with double bonds to PN solution (oleic, linoleic or linolenic acid, $50 \mathrm{mM}$ ), ${ }^{1} \mathrm{O}_{2}$ can also attack the double bonds leading to oxygen consumption. In our experimental setting, the rate of ${ }^{1} \mathrm{O}_{2}$ generation can be calculated. With regard to the absorption cross section of PN at $355 \mathrm{~nm}$ $\left(3.3 \times 10^{-17} \mathrm{~cm}^{2}\right)$ and the concentration of $200 \mu \mathrm{mol} \mathrm{L}^{-1}, 98 \%$ of laser photons are absorbed in the cuvette with a thickness of $1 \mathrm{~cm}$. The applied mean optical power of $50 \mathrm{~mW}$ yields $0.9 \times 10^{17}$ photons per second that are absorbed in the solution. The quantum yield of singlet oxygen $\Phi_{\Delta} \approx 1$ for $\mathrm{PN}^{15}$ provides a sufficiently high rate of ${ }^{1} \mathrm{O}_{2}$ generation of about $0.9 \times 10^{171} \mathrm{O}_{2}$ molecules per second. This value is clearly higher compared to the rate of oxygen molecules that disappear in linolenic acid solution showing a value of about $4 \times 10^{15}{ }^{1} \mathrm{O}_{2}$ molecules per second in our experimental setting. A fraction might be physically deactivated by e.g. the solvent molecules.

The values in Table 1 show that oxidation of fatty acids with double bonds such as oleic acid increased the oxygen consumption only to a small extent, from $0.9 \mu \mathrm{mol} \mathrm{L}^{-1} \mathrm{~s}^{-1}$ to $1.2 \mu \mathrm{mol} \mathrm{L}^{-1} \mathrm{~s}^{-1}$. In addition, the rate did not correlate with the number of double bonds (Table 1). To elucidate this process, we performed the experiments with the photo-stable TMPyP to generate ${ }^{1} \mathrm{O}_{2}$.

\section{Oxygen consumption in fatty acid solutions with the photosensitizer TMPyP}

TMPyP was excited with $532 \mathrm{~nm}$ laser light in the visible spectrum and $250 \mathrm{~mW}$ mean power for up to $10 \mathrm{~min}$. As for experiments with $\mathrm{PN}$, we calculated the rate of ${ }^{1} \mathrm{O}_{2}$ generation. An absorption cross section of TMPyP at $532 \mathrm{~nm}(1.5 \times$ $10^{-17} \mathrm{~cm}^{2}$ ), a concentration of $25 \mu \mathrm{mol} \mathrm{L}^{-1}$, a cuvette thickness of $1 \mathrm{~cm}$, and a power of $250 \mathrm{~mW}$ yield $1.3 \times 10^{17}$ photons per second that are absorbed in the solution. Since the quantum yield of ${ }^{1} \mathrm{O}_{2}$ of TMPyP is $\Phi_{\Delta} \approx 0.77,{ }^{30}$ we should have generated about $1.0 \times 10^{17}{ }^{1} \mathrm{O}_{2}$ molecules per second. This value is close to ${ }^{1} \mathrm{O}_{2}$ generation in experiments with $\mathrm{PN}$.

TMPyP in pure solution is physically and chemically stable even under long-lasting irradiation at $532 \mathrm{~nm}$ causing no oxygen consumption (data not shown). Oxygen consumption is zero in the presence of stearic acid within experimental accuracy. In the presence of the different fatty acids during irradiation, Fig. 1b shows a linear decrease of oxygen concentration in solution for long irradiation times. Compared to oleic acid $\left(1.2 \mu \mathrm{mol} \mathrm{L} \mathrm{L}^{-1} \mathrm{~s}^{-1}\right)$, the rate constant for linoleic acid is nearly doubled due to the presence of two isolated double bonds that lead to a higher reactivity towards ${ }^{1} \mathrm{O}_{2}$. In the case of linolenic acid (three double bonds), the rate constant is tripled as compared to oleic acid (Table 1). In conclusion, oxygen consumption with photostable TMPyP correlates with the number of double bonds.

However, after having established that there is oxygen consumption during irradiation of PN in ethanol at $355 \mathrm{~nm}$, in the following paragraph the reference photosensitizer PN is further investigated using the above-mentioned experimental settings. The aim is to gain more insights into the complex system consisting of a photounstable and oxygen consuming PS.

\section{Singlet oxygen generation of PN in pure ethanol solutions}

To elucidate further the properties of $\mathrm{PN}$ during ${ }^{1} \mathrm{O}_{2}$ generation, we investigated photostability and ${ }^{1} \mathrm{O}_{2}$ generation by photoactivated PN in pure ethanol. It is obvious that the less PS molecules are intact the less ${ }^{1} \mathrm{O}_{2}$ molecules can be generated by energy transfer. As for every PS, light-induced decomposition of PN would affect the quantitative ${ }^{1} \mathrm{O}_{2}$ detection and therefore, the interpretation of the luminescence data.

We dissolved PN in air-saturated ethanol at a concentration of $100 \mu \mathrm{M}$ and continuously irradiated for up to $30 \mathrm{~min}$ $(100 \mathrm{~mW}, 355 \mathrm{~nm})$. Prior to irradiation, the absorption crosssection of $\mathrm{PN}$ is $(3.3 \pm 0.2) \times 10^{-17} \mathrm{~cm}^{2}$ at $355 \mathrm{~nm}$. After $30 \mathrm{~min}$ of irradiation, the value decreases to $(0.6 \pm 0.2) \times 10^{-17} \mathrm{~cm}^{2}$, indicating a substantial change in PN molecules. HPLC of irradiated PN revealed that the PS completely disappeared in solution after about $30 \mathrm{~min}$ of irradiation and 12 products appeared (data not shown).

Additionally, we detected ${ }^{1} \mathrm{O}_{2}$ luminescence (detection time: $10 \mathrm{~s}$ ) at regular time intervals (3 $\mathrm{min})$ during the continuous irradiation time of $30 \mathrm{~min}$. We quantified the signal by temporal integration of the luminescence signal (Fig. 3). The total luminescence signal decreased rapidly with irradiation time showing a rate of about $2.7 \times 10^{-3} \mathrm{~s}^{-1}$ fitted by a monoexponential function within the first $4 \mathrm{~min}$. After that time, the decrease reduced and reached a nearly constant value after about 20 min of irradiation. The decrease of ${ }^{1} \mathrm{O}_{2}$ luminescence correlated with the decrease of PN absorption at $355 \mathrm{~nm}$. 


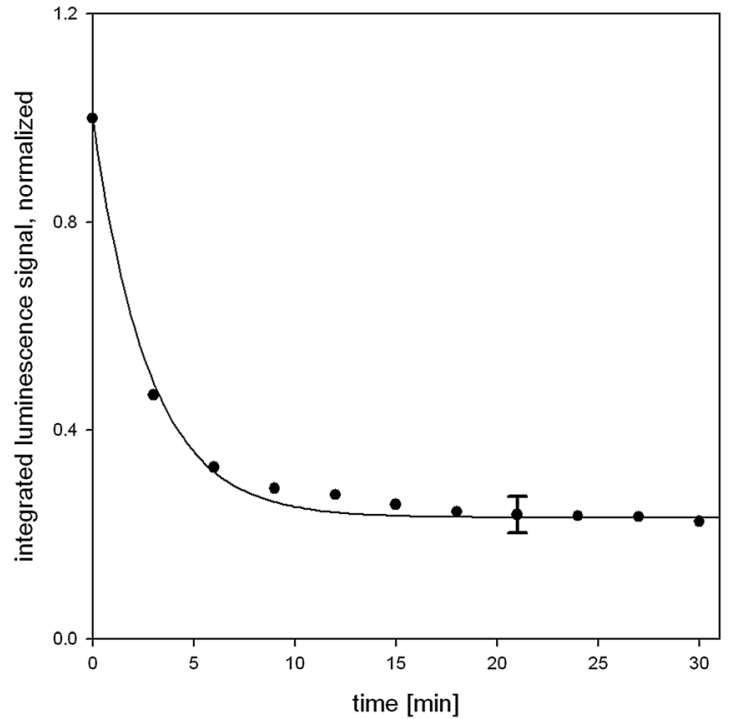

Fig. 3 The integrated time resolved ${ }^{1} \mathrm{O}_{2}$ luminescence signal at different irradiation times of $100 \mu \mathrm{mol} \mathrm{L}{ }^{-1} \mathrm{PN}$ dissolved in ethanol. The acquisition time of the luminescence signals was $10 \mathrm{~s}$ at regular time intervals of 3 min during a constant irradiation with $100 \mathrm{~mW}$ (355 nm) for $30 \mathrm{~min}$.

However, the luminescence of ${ }^{1} \mathrm{O}_{2}$ did not disappear although HPLC showed no PN after 30 min but only PN products (data not shown). These photoproducts also absorb at a wavelength of $355 \mathrm{~nm}$ and some of these PN products might generate ${ }^{1} \mathrm{O}_{2}$, possibly with different quantum yields. When reviewing the experiments above, the decrease of ${ }^{1} \mathrm{O}_{2}$ generation in the first 4 min should be mainly responsible for the attenuation of the rate constants in fatty acid solution that is obvious for times longer than 4 min of irradiation (Fig. 1a). The apparent photoinstability of PN for long irradiation times (minutes) should also be responsible for the lack of correlation between the rate constant of oxygen consumption and the number of double bonds in the respective fatty acid (Table 1).

When using photounstable PS such as PN, it is recommended to investigate the photophysical properties under the given experimental conditions and optimize given parameters such as irradiation intensities and irradiation times (minutes). The next paragraph shows that under optimized conditions the photophysical parameters such as the rate and rate constants of the given system PN in ethanol are not influenced and further do not influence data interpretation in more complex systems.

\section{Singlet oxygen generation of PN in pure ethanol solutions at different oxygen concentrations}

In this section, the investigation of the correlation between oxygen partial pressure and ${ }^{1} \mathrm{O}_{2}$ luminescence is presented, which was performed by applying different oxygen concentrations in solution. Using a concentration of $25 \mu \mathrm{mol} \mathrm{L} \mathrm{L}^{-1}$ in ethanol, PN was excited at $355 \mathrm{~nm}$. By fitting eqn (1) to the time-resolved luminescence signal of ${ }^{1} \mathrm{O}_{2}$, the rise and decay rates $\beta_{1}$ and $\beta_{2}$ can be obtained. The evaluation of rise and decay rates enables the determination of the rates and the rate constants of the underlying differential equation system.
The latter describes the coupled system (energy transfer) of PS and oxygen, which is described in detail elsewhere. ${ }^{21}$

When taking the previous results with PN into account, the experiment was performed under two different conditions in order to optimize the experimental conditions and in order to investigate the potential influence of the decomposition of the PN molecule on the rise and decay rates. Firstly, we used a short exposure time of $10 \mathrm{~s}$ and the solution was exchanged after two measurements. Secondly, we performed the same experiment without exchanging the PN solutions during the entire procedure and extended the luminescence detection time from 10 to $20 \mathrm{~s}$. The rates were measured at different oxygen concentrations ( 0 to $1.85 \mathrm{mmol} \mathrm{L}^{-1}$ ) by flowing the solution with nitrogen prior to irradiation. The actual oxygen concentration in solution was measured using the needle sensor. ${ }^{36}$ Using the differential equation system, ${ }^{21}$ we calculated the theoretical values for a known and constant oxygen concentration and fitted them to experimental values (solid lines in Fig. 4).

In both experimental settings, the values of $\beta_{1}$ and $\beta_{2}$ did not change in spite of the beginning degradation of the PS. In the inset of Fig. 4 the measured values at low oxygen concentrations are depicted. Thus, the change in PN molecules does not affect the evaluation of the rates and rate constants of the coupled differential equation system when using our experimental conditions, in particular short irradiation times.

In addition, the rates $\beta_{1}$ and $\beta_{2}$ of the luminescence signal of ${ }^{1} \mathrm{O}_{2}$ were determined at a fixed oxygen concentration $\left(370 \mu \mathrm{mol} \mathrm{L}^{-1}\right)$ but at different PN concentrations up to $50 \mu \mathrm{mol} \mathrm{L}^{-1}$ (data not shown). Here, the rates and rate constants were not affected by the photoinstability of PN.

In light of these results and using the appropriate experimental setting, we now can neglect effects of PN photoinstability and subsequent oxygen consumption on our luminescence detection. As a consequence, linoleic acid with two double bonds was added to solution to investigate the dependence of the rate and rate constants in systems that can chemically quench ${ }^{1} \mathrm{O}_{2}$

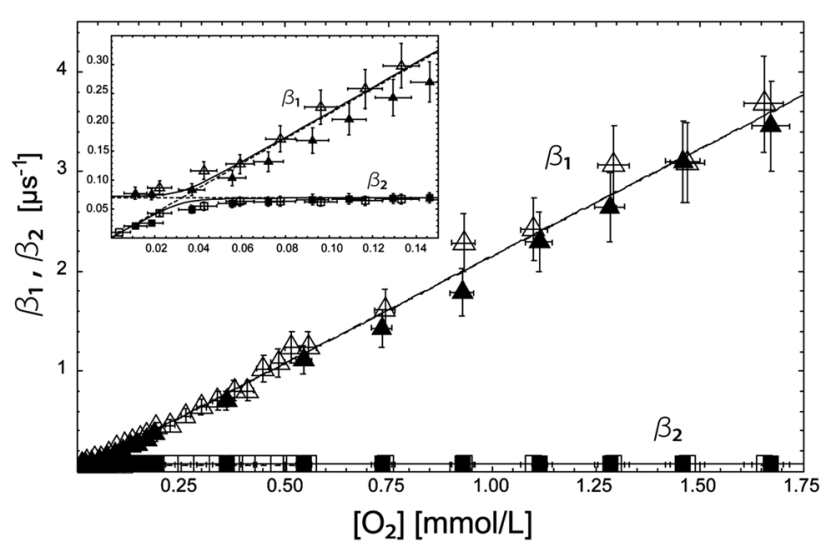

Fig. 4 Dependence of the rise rate $\beta_{1}$ and decay rate $\beta_{2}$ of the luminescence of ${ }^{1} \mathrm{O}_{2}$ on the concentration of oxygen ( $25 \mu \mathrm{mol} \mathrm{L}{ }^{-1}$ PN dissolved in ethanol). The open symbols show the values without a change of the solution during measurement. Closed symbols show the values with a change of the solution after two single measurements. The area around the crossing point is depicted in the inset. 
which is pertinent to biological systems such as single cells or cell suspensions.

\section{Singlet oxygen generation of PN in linoleic acid solution at different oxygen concentrations}

Comparable to solutions without fatty acids, the rise rate $\beta_{1}$ and the decay rate $\beta_{2}$ of the ${ }^{1} \mathrm{O}_{2}$ luminescence were determined at different oxygen concentrations in the presence of linoleic acid. The short detection time of $10 \mathrm{~s}$ yielded a sufficient ${ }^{1} \mathrm{O}_{2}$ luminescence signal. Using the differential equation system, ${ }^{21}$ we calculated the luminescence rates at a known and constant oxygen concentration in fatty acid solution and fitted them to the experimental values (solid lines, Fig. 5). The deviations of the measured decay rates $\beta_{2}$ from the calculated theoretical values are in the range of experimental accuracy.

The rise rates $\beta_{1}$ of the luminescence signal for linoleic acid deviate from the calculated values (solid lines, Fig. 5a), in particular at high oxygen concentrations. As already mentioned above, oxygen is consumed by $\mathrm{PN}$ and oxidizable fatty acids. ${ }^{25}$

At high oxygen concentrations and assuming no energy back transfer, ${ }^{21}$ the meanings of the rates $\beta_{1}$ and $\beta_{2}$ are as follows:

$$
\begin{gathered}
\beta_{1}=K_{\mathrm{T}_{1}}=k_{\mathrm{T}_{1}}+\left(k_{\mathrm{T}_{1} \mathrm{O}_{2}}+k_{\mathrm{T}_{1} \Delta}\right)\left[\mathrm{O}_{2}\right]+k_{\mathrm{T}_{1} \mathrm{SO}}[\mathrm{P}]+k_{\mathrm{T}_{1} \mathrm{Q}}[\mathrm{Q}] \\
\beta_{2}=K_{\Delta}=k_{\Delta}+k_{\Delta \mathrm{SO}}[\mathrm{P}]+k_{\Delta \mathrm{Q}}[\mathrm{Q}]
\end{gathered}
$$

In eqn (2) and (3), [P] represents the photosensitizer concentration and [Q] represents the quencher concentration. Eqn (2) shows that $K_{\mathrm{T}_{1}}$ and thus $\beta_{1}$ depend on the oxygen concentration. Any change in the local oxygen concentration during measurement will be reflected in the rise rate. In contrast to $K_{\mathrm{T}_{1}}\left(\beta_{1}\right)$, the decay rate $K_{\Delta}\left(\beta_{2}\right)$ is independent of the oxygen concentration.

Furthermore, the oxygen consumption is maximal in the center of the excitation beam in the middle of the cuvette. This change in local oxygen concentration causes a gradient of oxygen concentration that should be balanced by oxygen diffusion. ${ }^{10,37}$ The small diffusion coefficients for oxygen in solvents may hamper the diffusion-controlled process of ${ }^{1} \mathrm{O}_{2}$ generation. The average value of the square of distance $d$, which an $\mathrm{O}_{2}$ molecule travels during time $t$, depends on its diffusion coefficient $D_{0}$ according to $d^{2}=6 D_{0} t .^{28} D_{0}$ is $2.64 \times 10^{-5} \mathrm{~cm}^{-2} \mathrm{~s}^{-1}$ for oxygen in ethanol $^{37}$ at $303 \mathrm{~K}$ and the laser spot size in the cuvette is $8 \mathrm{~mm}$. Thus, oxygen redistribution lasts several minutes. A magnetic stirrer was switched on during irradiation to minimize the effect of the oxygen gradient. Now, the detected rise rates $\beta_{1}$ of ${ }^{1} \mathrm{O}_{2}$ luminescence fitted better to the theoretical lines (Fig. 5b).

It is assumed that such an enforced oxygen redistribution should fail inside living cells or bacteria, in which the diffusion coefficient is even smaller as compared to pure solvents. ${ }^{38}$ Thus, it is important to consider oxygen consumption when detecting and interpreting ${ }^{1} \mathrm{O}_{2}$ luminescence (rise and decay times) in environments that contain fatty acids, in particular in living cells or bacteria. In future, the theoretical values of ${ }^{1} \mathrm{O}_{2}$ generation have to be adapted to oxygen consumption in the case of high concentrations of oxygen consumers such as unsaturated fatty acids.
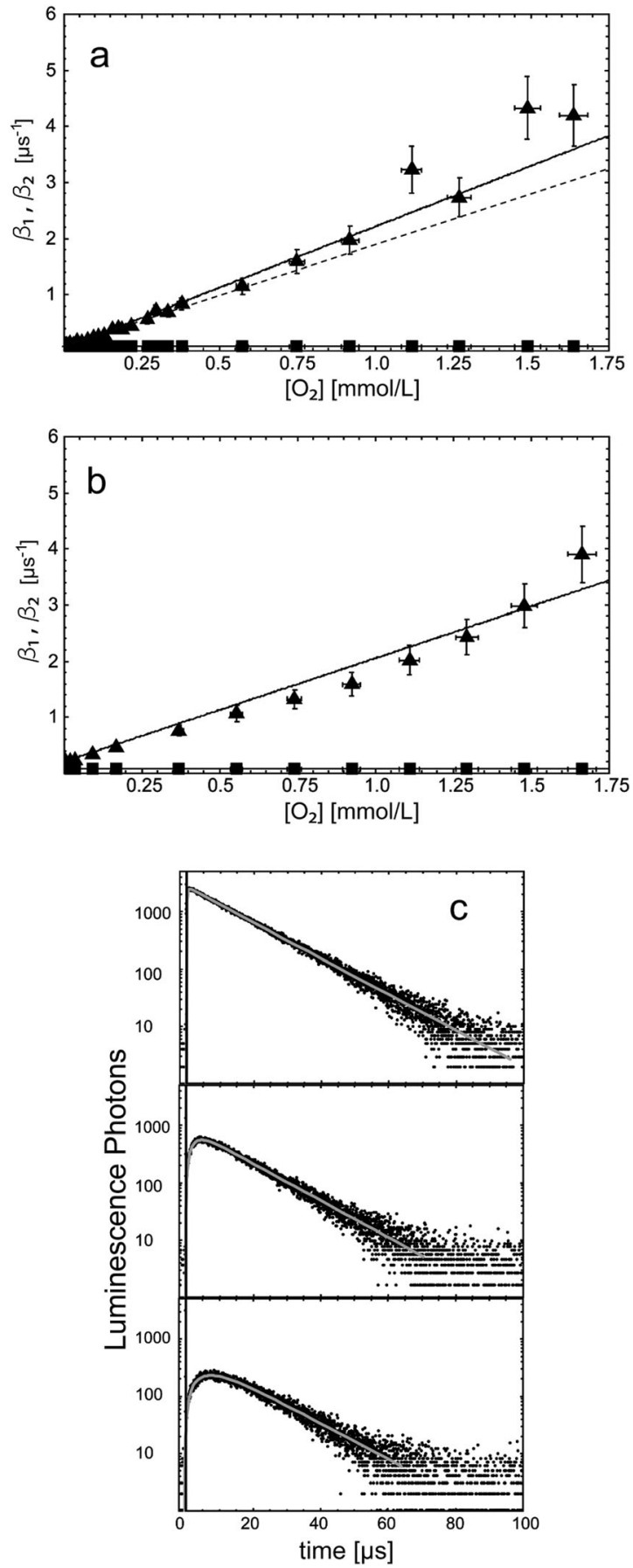

Fig. 5 Dependence of the rise rate $\beta_{1}$ (triangles) and the decay rate $\beta_{2}$ (squares) of the ${ }^{1} \mathrm{O}_{2}$ luminescence signal on the concentration of oxygen with $25 \mu \mathrm{mol} \mathrm{L}{ }^{-1}$ PN and with linoleic acid $(18: 2)$. The detection was performed without (a) and with magnetic stirring (b). For comparison, the theoretical fit of data in Fig. 5b is added as a dashed curve to Fig. $5 \mathrm{a} .{ }^{1} \mathrm{O}_{2}$ luminescence signals are shown for three different oxygen concentrations (c), $1850 \mu \mathrm{mol} \mathrm{L} \mathrm{L}^{-1}$ (top, $\tau_{\mathrm{R}}=0.3 \mu \mathrm{s}$ ), $222 \mu \mathrm{mol} \mathrm{L}{ }^{-1}$ (middle, $\tau_{\mathrm{R}}=2.2 \mu \mathrm{s}$ ), and $74 \mu \mathrm{mol} \mathrm{L}{ }^{-1}$ (bottom, $\tau_{\mathrm{R}}=4.7 \mu \mathrm{s}$ ).

\section{Luminescence experiments at different PN concentrations}

The effect of oxygen gradients was investigated in the following experiment. PN was exemplarily added (up to $50 \mu \mathrm{mol} \mathrm{L} \mathrm{L}^{-1}$ ) to solutions of linoleic acid $\left(50 \mathrm{mmol} \mathrm{L}^{-1}\right)$. We determined the 


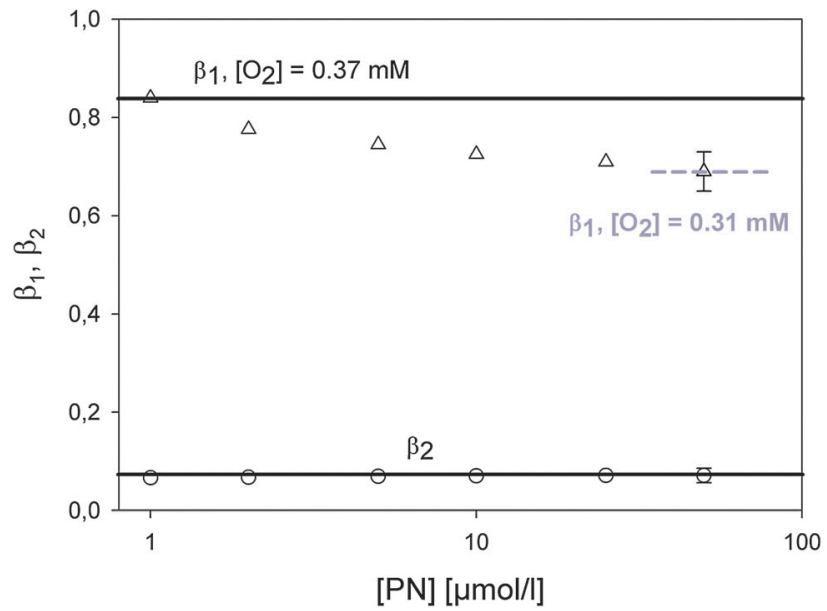

Fig. 6 Dependence of $\beta_{1}$ and $\beta_{2}$ on the concentration of PN with linoleic acid in solution. The black solid lines indicate the theoretical values for $\beta_{1}$ and $\beta_{2}$ for a constant oxygen concentration of $370 \mu \mathrm{mol} \mathrm{L}{ }^{-1}$. The grey dashed line represents the theoretical value for an oxygen concentration at $\sim 310 \mu \mathrm{mol} \mathrm{L^{-1 }}$ that is obtained due to oxygen consumption.

rates of ${ }^{1} \mathrm{O}_{2}$ luminescence at a fixed oxygen concentration

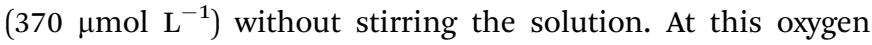
concentration, the fit of luminescence signals is optimal because of the longer rise time of the luminescence, which reflects the rate $K_{\mathrm{T}_{1}}$ (Fig. $5 \mathrm{c}$ ).

The values (solid lines in Fig. 6) of the decay rates $\beta_{2}$, which are calculated by solving the differential equation system at a fixed oxygen concentration, fitted within experimental accuracy to the experimental values. The calculated values of the rise rates $\beta_{1}$ fit the experimental values only at very small PN concentrations. The generation rate of ${ }^{1} \mathrm{O}_{2}$ is about 4.5 to $45 \times 10^{15} \mathrm{~s}^{-1}$ ( 1 to $10 \mu \mathrm{mol} \mathrm{L}{ }^{-1}$ of $\left.\mathrm{PN}\right)$. With increasing $\mathrm{PN}$ concentrations in solution, the respective rise rate $\beta_{1}$ of ${ }^{1} \mathrm{O}_{2}$ decreases. The values were recalculated and $\beta_{1}\left(50 \mu \mathrm{mol} \mathrm{L} \mathrm{L}^{-1}\right.$ PN) fitted now to an oxygen concentration of $310 \mu \mathrm{mol} \mathrm{L} \mathrm{L}^{-1}$ (Fig. 6). Thus, the deactivation of the triplet $T_{1}$ state corresponds to a local oxygen concentration of $310 \mu \mathrm{mol} \mathrm{L}{ }^{-1}$, which is confined to the laser beam inside the cuvette.

The time span of ${ }^{1} \mathrm{O}_{2}$ generation and its detection was $5 \mathrm{~s}$. This yields a rate constant of $12 \mu \mathrm{mol} \mathrm{L^{-1 }} \mathrm{s}^{-1}$ for oxygen consumption. This value is larger as expected when considering the values determined above with about $1.6 \mu \mathrm{mol} \mathrm{L}^{-1} \mathrm{~s}^{-1}$ for linoleic acid using the needle sensor. Thus, the portion of fatty acid molecules that undergo peroxidation should be clearly higher in the center of the excitation beam as assumed above.

Obviously, the rate $K_{\mathrm{T}_{1}}$ of the luminescence signal seems to be a precise and fast detector of oxygen concentration at the site of ${ }^{1} \mathrm{O}_{2}$ generation.

\section{Conclusion}

The photophysical and photochemical stability is a major prerequisite for all PS when applied in any kind of photodynamic processes such as PDT or when applied in ${ }^{1} \mathrm{O}_{2}$ luminescence experiments. Showing a quantum yield of ${ }^{1} \mathrm{O}_{2}$ generation close to unity, $\mathrm{PN}$ is frequently used as a reference PS, however, long time irradiation should be avoided in ethanol solution. The molecule is photo-unstable consuming oxygen via radical reactions, in particular abstracts hydrogen from other molecules (e.g. fatty acids). However, by optimizing experimental conditions such as short time excitation of a few seconds, PN is sufficiently photo-stable to be used in experiments with ${ }^{1} \mathrm{O}_{2}$. Comparable experiments should be performed for all other PS before using them in a more complex system in combination with cellular components and even in cell experiments. TMPyP has been shown to be a suitable candidate for such experiments.

Moreover, the deactivation of the PS triplet $T_{1}$ state can provide an indication of the actual oxygen concentration at the site of ${ }^{1} \mathrm{O}_{2}$ generation as well as the oxygen consumption by biomolecules like fatty acids. The time resolved ${ }^{1} \mathrm{O}_{2}$ luminescence might become an additional tool for a fast and precise detection of oxygen concentration, even in living cells during PDT.

To detect time-resolved ${ }^{1} \mathrm{O}_{2}$ luminescence, other researchers also frequently apply the experimental arrangement used in our experiments. The results show that the use of laser excitation, which exhibits a focused beam with a Gaussian intensity profile, can lead to oxygen gradients due to oxygen consumption via ${ }^{1} \mathrm{O}_{2}$ reactions at the site of irradiation. This is of particular importance when oxygen diffusion is hampered, e.g. by cellular structures in living cells. Depending on the irradiation and detection time, the luminescence signals of ${ }^{1} \mathrm{O}_{2}$ should change. One important aspect such as the oxygen consumption by fatty acids as well as by proteins has to be considered when interpreting luminescence signals originating from ${ }^{1} \mathrm{O}_{2}$. Further development of methodology might be necessary in future to consider or to avoid such gradients.

\section{Acknowledgements}

The present work was supported by two grants of the German Research Foundation (DFG), grant number GO2340/1-1 (Anita Gollmer) and RE3323/2-1 (Johannes Regensburger). The authors declare no conflict of interest.

\section{References}

1 N. Lane, Oxygen: the molecule that made the world, Oxford University Press, 2002.

2 P. R. Ogilby, Chem. Soc. Rev., 2010, 39, 3181-3209.

3 R. W. Redmond and I. E. Kochevar, Photochem. Photobiol., 2006, 82, 1178-1186.

4 E. L. Clennan and A. Pace, Tetrahedron, 2005, 61, 6665-6691.

5 R. D. Scurlock, B. J. Wang, P. R. Ogilby, J. R. Sheats and R. L. Clough, J. Am. Chem. Soc., 1995, 117, 10194-10202.

6 P. Agostinis, K. Berg, K. A. Cengel, T. H. Foster, A. W. Girotti, S. O. Gollnick, S. M. Hahn, M. R. Hamblin, A. Juzeniene, D. Kessel, M. Korbelik, J. Moan, P. Mroz, D. Nowis, J. Piette, B. C. Wilson and J. Golab, Ca-Cancer J. Clin., 2011, 61, 250-281. 
7 T. Maisch, S. Hackbarth, J. Regensburger, A. Felgentraeger, W. Baeumler, M. Landthaler and B. Roeder, Journal Der Deutschen Dermatologischen Gesellschaft, 2011, 9, 360-366.

8 M. C. DeRosa and R. J. Crutchley, Coord. Chem. Rev., 2002, 233, 351-371.

9 G. B. Kharkwal, S. K. Sharma, Y.-Y. Huang, T. Dai and M. R. Hamblin, Lasers Surg. Med., 2011, 43, 755-767.

10 M. K. Kuimova, G. Yahioglu and P. R. Ogilby, J. Am. Chem. Soc., 2009, 131, 332-340.

11 R. L. Jensen, J. Arnbjerg and P. R. Ogilby, J. Am. Chem. Soc., 2012, 134, 9820-9826.

12 J. Baier, T. Maisch, M. Maier, M. Landthaler and W. Baumler, J. Invest. Dermatol., 2007, 127, 1498-1506.

13 M. T. Jarvi, M. J. Niedre, M. S. Patterson and B. C. Wilson, Photochem. Photobiol., 2006, 82, 1198-1210.

14 T. Maisch, J. Baier, B. Franz, M. Maier, M. Landthaler, R. M. Szeimies and W. Bäumler, Proc. Natl. Acad. Sci. U. S. A., 2007, 104, 7223-7228.

15 S. Nonell, M. Gonzalez and R. Trull, Afinidad, 1993, 448, 445-450.

16 K. Chen, A. Preuss, S. Hackbarth, M. Wacker, K. Langer and B. Roder, J. Photochem. Photobiol. B, 2009, 96, 66-74.

17 S. Hackbarth, J. Schlothauer, A. Preuss and B. Roder, J. Photochem. Photobiol. B, 2010, 98, 173-179.

18 P. F. Conn, W. Schalch and T. G. Truscott, J. Photochem. Photobiol. B, 1991, 11, 41-47.

19 M. A. Rodgers, Photochem. Photobiol., 1983, 37, 99-103.

20 J. Regensburger, T. Maisch, A. Felgentraeger, F. Santarelli and W. Baeumler, J. Biophotonics, 2010, 3, 319-327.

21 J. Baier, T. Fuß, C. Pöllmann, C. Wiesmann, K. Pindl, R. Engl, D. Baumer, M. Maier, M. Landthaler and W. Bäumler, J. Photochem. Photobiol. B, 2007, 87, 163-173.
22 J. G. Parker and W. D. Stanbro, Prog. Clin. Biol. Res., 1984, 170, 259-284.

23 T. Breitenbach, M. K. Kuimova, P. Gbur, S. Hatz, N. B. Schack, B. W. Pedersen, J. D. Lambert, L. Poulsen and P. R. Ogilby, Photochem. Photobiol. Sci., 2009, 8, 442-452.

24 H. P. Wang, S. Y. Qian, F. Q. Schafer, F. E. Domann, L. W. Oberley and G. R. Buettner, Free Radicals Biol. Med., 2001, 30, 825-835.

25 A. W. Girotti, Free Radicals Biol. Med., 2008, 44, 956-968.

26 K.-K. Iu and P. R. Ogilby, J. Phys. Chem., 1987, 91, 1611-1617.

27 A. W. Girotti, J. Lipid Res., 1998, 39, 1529-1542.

28 C. Schweitzer and R. Schmidt, Chem. Rev., 2003, 103, 1685-1757.

29 E. F. F. da Silva, B. W. Pedersen, T. Breitenbach, R. Toftegaard, M. K. Kuimova, L. G. Arnaut and P. R. Ogilby, J. Phys. Chem. B, 2012, 116, 445-461.

30 J. W. Snyder, J. D. Lambert and P. R. Ogilby, Photochem. Photobiol., 2006, 82, 177-184.

31 J. Baier, T. Maisch, J. Regensburger, M. Loibl, R. Vasold and W. Baumler, J. Biomed. Opt., 2007, 12, 064001.

32 K. A. Schenkman, Am. J. Physiol., 2001, 281, H2463-2472.

33 P. J. Quinn and D. Chapman, Crit. Rev. Biochem., 1980, 8, 1-117.

34 N. A. Kuznetsova, O. L. Kaliya, N. D. Sergeeva and S. L. Solodar, Zh. Org. Khim., 1987, 23, 388-392.

35 E. Oliveros, S. Bossmann, S. Nonell, C. Marti, G. Heit, G. Tröscher, A. Neuner, C. Martinez and A. Brauna, New J. Chem., 1999, 23, 85-93.

36 D. Baumer, M. Maier, R. Engl, R. M. Szeimies and W. Baumler, Chem. Phys., 2002, 285, 309-318.

37 N. N. Kruk, J. Appl. Spectrosc., 2008, 75, 174-180.

38 S. Hatz, L. Poulsen and P. R. Ogilby, Photochem. Photobiol., 2008, 84, 1284-1290. 